Northwest: A literature review and synthese. Research Contribution 50, College of Forestry, Oregon State University. $99 \mathrm{p}$.

Johnson, G. R. and B. L. GARTNER (2006): Genetic variation in basic density and modulus of elasticity of coastal Douglas-fir. Tree Genetics and Genomes 3: 25-33.

Johnson, G. R., R. A. SNiEzko and N. L. MANDEL (1997): Age trends in Douglas-fir genetic parameters and implications for optimum selection age. Silvae Genetica 46: 349-358.

KiI, H., N. I. Fujimoto, Y. Murase, T. Kawano, Y. AshihaRA, Y. Kinoshita, M. Mikeda, S. Tsushima and T. MAmedA (2003): Strength properties of sugi (Cryptomeria japonica) grown in Oita prefecture - Young's modulus of logs. Science Bulletin of the Faculty of Agriculture, Kyusha University. 58(1/2): 43-54.

KInG, J. N., F. C. YeH, J. C. Heaman and B. P. DanciK (1992): Selection of crown form traits in controlled crosses of coastal Douglas-fir. Silvae Genetica 41: 362-370.

KumAR, S. (2004): Genetic parameter estimates for wood stiffness, strength, internal checking, and resin bleeding for radiata pine. Canadian Journal of Forest Research 34: 2601-2610.

Kumar, S., R. D. Burdon and G. T. Stovold (2008): Wood properties and stem diameter of Pinus radiata in New Zealand: genetic parameter estimates of clonal and seedling material. New Zealand Journal of Forestry Science 38(1): 88-101.

Kumar, S., K. J. S. Jayawickrama, J. Lee and M. LausBERG (2002): Direct and indirect measures of stiffness and strength show high heritability in a wind-pollinated radiata pine progeny test in New Zealand. Silvae Genetica 51: 256-261.

Kumar, S., H. S. Dungey and A. C. Matheson (2006): Genetic parameters and strategies for genetic improvement of stiffness in radiata pine. Silvae Genetica 55: $77-84$.
Li, X, D. A. Huber, G. L. Powell, T. L. White and G. F. PETER (2007): Breeding for improved growth and juvenile corewood stiffness in slash pine. Canadian Journal of Forest Research 37: 1886-1893.

Littell, R. C., G. A. Milliken, W. W. Stroup and R. D. WolFINGER (1996): SAS system for mixed models. SAS Institute, Cary, North Carolina.

LYNCH, M. and B. WALSH (1998): Genetics and analysis of quantitative traits. Sinauer Associates, Inc., Sunderland, Massachusetts.

Magnussen, S. and C. T. Keith (1990): Genetic improvement of volume and wood properties of jack pine: selection strategies. Forestry Chronicle 66(3): 281-286.

Matheson, A. C., W. J. Gapare, J. Ilic and H. X. WU (2008): Inheritance and genetic gain in wood stiffness in radiata pine assessed acoustically in young standing trees. Silvae Genetica 57: 56-64.

Silen, R. and J. WheAT (1979): Progressive tree improvement program in coastal Douglas-fir. J. Forestry 44: 78-83.

Toulmin, M. J. and C. A. RAYMond (2007): Developing a sampling strategy for measuring acoustic velocity in standing Pinus radiata using the TreeTap time of flight tool. New Zealand Journal of Forestry Science 37: 96-111.

VAN WYK, G. V. (1990): Genetic improvement of timber yield and wood quality in Eucalyptus grandis (Hill) Maiden. Part 1. Genetic parameters of growth characteristics. South African Forestry Journal 153: 1-11.

Weilinga, B., C. A. Raymond, R. James and A. C. MatheSON (2009a): Genetic parameters and genotype by environment interactions for green and basic density and stiffness of Pinus radiata D. Don estimated using acoustics. Silvae Genetica 58: 112-122.

Weilinga, B., C. A. Raymond, R. James and A. C. MatheSON (2009b): Effect of green density values on Pinus radata stiffness estimation using a stress=wave technique. N.Z.J. For. Sci. 39: 71-79.

\title{
An Optimised Protocol for Fluorescent-dUTP Based SSR Genotyping and its Application to Genetic Mapping in Eucalyptus
}

\author{
By F. LI and S. GAN*) \\ Research Institute of Tropical Forestry, Chinese Academy of Forestry, Longdong, Guangzhou 510520, \\ People's Republic of China
}

(Received $12^{\text {th }}$ January 2010)

\begin{abstract}
Integration of fluorescent-dUTP in polymerase chain reaction (PCR) appears to be a sound method for fluorescence labelling of amplicons in genotyping with simple sequence repeats (SSRs) using an automated sequence

\footnotetext{
*) Corresponding author: SIMING GAN. Tel. +86 2087032402 ,
} Fax +86 2087031622 . E-mail: Siming.Gan@ritf.ac.cn
\end{abstract}

analyser. However, the method has not been explored in terms of performance optimisation and cost control. In this paper, we optimised the protocol for fluorescentdUTP based SSR genotyping in a case study with Eucalyptus. A combination of low dNTP concentration $(25 \mu \mathrm{M}$ each) in PCR reaction and a touchdown PCR programme contributed to increase dramatically the fluorescent intensity of SSR amplicons, thereby facilitating 
accurate and multiplexed scoring of SSR alleles. The usefulness of the optimised protocol was demonstrated in its application to genetic mapping of SSR loci onto $E$. urophylla and $E$. tereticornis linkage maps constructed previously. The protocol optimised here would provide a reliable and economical assay for sequencer-based SSR genotyping in a wide range of biological applications.

Key words: Simple sequence repeats (SSRs), genotyping, fluorescent-dUTP, Eucalyptus, genetic mapping.

\section{Introduction}

Simple sequence repeats (SSRs), or microsatellites, are among the most important categories of molecular markers owing to their co-dominant, reproducible and highly polymorphic nature (TAUZ, 1989; PowELL et al., 1996; SCHLÖTTERER, 2004). They comprise the core marker system of the polymerase chain reaction (PCR) based molecular markers and have become the marker of choice for a wide range of biological applications (NGUYEN and Wu, 2005; PASHLEY et al., 2006). However, detection of SSR alleles in an accurate, economical and high-throughput way appears to remain an important challenge.

As accuracy and throughput are concerned, detection of SSRs has been preferentially directed towards a fluorescent dye based high-throughput system using an automated sequence analyser (NGUYEN and WU, 2005). In this context, a number of methods have emerged for fluorescence labelling of SSR amplicons, including fluorophore modification of a PCR ingredient, e.g. primer, universal M13 primer or dNTP (dATP, dTTP, dCTP or dGTP), and post-PCR labelling (SCHUELKE, 2000; NGUYEN and WU, 2005). However, these methods are cost expensive (e.g. primer labelling), imprecise in estimating amplicon size (e.g. dNTP labelling due to variability in the number of incorporated fluorescent nucleotides) or inconvenient to implement (e.g. postPCR labelling). In contrast, integration of fluorescentdUTP (F-dUTP) in PCR reaction appears to be a sound choice for fluorescence labelling of amplicons in SSR genotyping (MAGNUSSON et al., 1996), and has been effectively applied in several reports (KLEVYTSKA et al., 2001; NAgaraJU et al., 2002; Gilmore and Peakall, 2003; Williams and Dewoody, 2003; MacAvoy et al., 2007; WoOlBRIGHT et al., 2008; Busch et al., 2009). However, the majority of previous reports adopted the routine reaction composition and/or normal PCR programme, and the possibility of multiplexed detection on a sequencer has not been explored thoroughly. Thus, the method needs to be optimised in terms of performance optimisation and cost control.

The genus Eucalyptus constitutes the most widely planted hardwoods in the world, with a global total of plantations more than 17.8 million ha (FAO, 2000). Its importance has evoked many efforts in genetic and genomic studies. To date, a large number of SSRs have been developed and widely used in studies with Eucalyptus species (GratTAPAGLIA and KIRST, 2008; YASODHA et al., 2008). Although several approaches have been successfully used for eucalypt SSR genotyping, including Metaphor agarose gel electrophoresis (MAGE; BRON-
DANI et al., 1998; AGRAMA et al., 2002), polyacrylamide gel electrophoresis (PAGE; BRONDANI et al., 1998; THAMARUs et al., 2002), fluorescent primer assay (JONES et al., 2002; THAMARUs et al., 2002; OTTEWELL et al., 2005) and universal fluorescent M13 primer assay (OTTEWELL et al., 2005), they are still limited in throughput (e.g. MAGE and PAGE) as well as other aspects as stated above.

In this study, we optimised a protocol for F-dUTP based SSR genotyping with an objective to establish a reliable procedure for economical, accurate and fast detection of SSR alleles using an automated sequence analyser. The usefulness of the protocol was demonstrated in efficient application to genetic mapping of SSRs in Eucalyptus.

\section{Materials and Methods}

\section{Plant material and DNA extraction}

A mapping population of $E$. urophylla $\left(\mathrm{P}_{1}, \mathrm{UX}-30\right) \times$ E. tereticornis $\left(\mathrm{P}_{2}, \mathrm{~T} 4305\right)$ reported previously (GAN et al., 2003) was employed in this study. The maternal parent $\left(\mathrm{P}_{1}\right)$ was used for PCR optimisation in F-dUTP based SSR detection. The mapping population was used for genetic mapping of SSR loci, and its size decreased from 82 to 54 sibs due to lethal damages by diseases, pests and other reasons during field conservation. Genomic DNA was extracted using a CTAB procedure (DOYLE and DOYLE, 1990) modified by adding 5\% polyvinylpyrrolidone (PVP) and $2 \% \beta$-mercaptoethanol to the extraction buffer (GAN et al., 2003), and DNA concentration was determined by electrophoresis on $1.0 \%$ agarose gel stained with 1:20 GoldView (a substitute of ethidium bromide; SBS Genetech Co., Beijing, China) with comparisons made to GeneRuler ${ }^{\mathrm{TM}} 100 \mathrm{bp}$ DNA Ladder (Fermentas International Inc., Burlington, Canada).

\section{SSR markers and PCR optimisation}

A total of 12 SSR markers that could generate apparently single fragment against $\mathrm{P}_{1}$ in PCR under a routine reaction composition and a normal programme were used in this study (Table 1). The repeat motif, primer sequences and GenBank accession number of each SSR were as described in BRONDANI et al. (2006). Primers were synthesized by Invitrogen Co. (Shanghai, China). The routine reaction of $10 \mu \mathrm{L}$ was composed of $1 \mathrm{x}$ buffer (100 mM Tris-HCl pH9.0, $80 \mathrm{mM}\left(\mathrm{NH}_{4}\right)_{2} \mathrm{SO}_{4}, 100 \mathrm{mM}$ $\mathrm{KCl}$ and $0.5 \% \mathrm{NP}-40), 2.0 \mathrm{mM} \mathrm{MgCl}_{2}, 200 \mu \mathrm{M}$ each dNTP, $0.5 \mu \mathrm{M}$ forward primer, $0.5 \mu \mathrm{M}$ reverse primer, 1 U Taq DNA polymerase (Biocolors Technology Co., Shanghai, China) and about $5 \mathrm{ng}$ DNA template of $\mathrm{P}_{1}$. Amplification was performed on a DNA Engine thermal cycler (Bio-Rad, Hercules, CA, USA) following the normal programme of $94^{\circ}$ for $4 \mathrm{~min}$; 35 cycles of $94^{\circ}$ for $30 \mathrm{~s}, 56^{\circ}$ or $60^{\circ}$ for $30 \mathrm{~s}$ and $72^{\circ}$ for $1 \mathrm{~min}$; and a final extension at $72^{\circ}$ for $10 \mathrm{~min}$. The PCR products were checked through electrophoresis on $1.5 \%$ agarose gels containing 1:20 GoldView (SBS Genetech Co.) and photographed with Photoprint 215SD (Vilber Lourmat Co., Marne la Vallée, France).

Optimisation of PCR procedure for F-dUTP based SSR genotyping was conducted for two factors, dNTP concen- 
Table 1. - SSR markers and their segregations among the mapping population of $E$. urophylla $\left(\mathrm{P}_{1}\right) \times E$. tereticornis $\left(\mathrm{P}_{2}\right) . P$-values indicate the significance of the segregation deviation of a SSR marker from the expected Mendelian inheritance. The repeat motif, primer sequences and GenBank accession number of each SSR could be found in BRONDANI et al. (2006). No allele fluorescent signal was detected in Embra177, and only a monomorphic allele was shown in Embra333 over the mapping population.

\begin{tabular}{rllllrl}
\hline No. & Marker & $\begin{array}{c}T_{\mathrm{m}} \\
\left({ }^{\circ}\right)\end{array}$ & $\begin{array}{c}\text { Parental } \\
\text { configuration } \\
\left(\mathrm{P}_{1} \times \mathrm{P}_{2}\right)\end{array}$ & \multicolumn{1}{c}{ Segregation } & $\begin{array}{c}\chi^{2} \\
\text { value }\end{array}$ & $P$ \\
\hline 1 & Embra203 & 56 & $a b \times a c$ & $a a: a b: a c: b c=28: 5: 5: 16$ & 26.74 & $<0.001$ \\
2 & Embra227 & 56 & $a b \times c d$ & $a c: a d: b c: b d=9: 11: 7: 10$ & 0.95 & $>0.05$ \\
3 & Embra139 & 56 & $a b \times a c$ & $a a: a b: a c: b c=24: 17: 9: 4$ & 17.26 & $<0.001$ \\
4 & Embra147 & 56 & $a b \times a c$ & $a a: a b: a c: b c=18: 15: 8: 13$ & 3.93 & $>0.05$ \\
5 & Embra29 & 56 & $a 0 \times b 0$ & $00: a 0: b 0: b c=24: 6: 16: 8$ & 15.04 & $<0.01$ \\
6 & Embra116 & 56 & $a a \times a b$ & $a a: a b \quad=27: 27$ & 0.0 & $>0.05$ \\
7 & Embra219 & 60 & $a b \times a c$ & $a a: a b: a c: b c=11: 11: 18: 13$ & 2.47 & $>0.05$ \\
8 & Embra333 & 60 & $a a \times a a$ & & & \\
9 & Embra177 & 60 & & & & \\
10 & Embra186 & 60 & $a b \times c d$ & $a c: a d: b c: b d=11: 17: 10: 9$ & 3.30 & $>0.05$ \\
11 & Embra173 & 60 & $a c \times b 0$ & $a b: a 0: b c: c 0=17: 17: 8: 8$ & 6.48 & $>0.05$ \\
12 & Embra189 & 60 & $a b \times a c$ & $a a: a b: a c: b c=11: 20: 11: 10$ & 5.08 & $>0.05$ \\
\hline
\end{tabular}

tration and PCR programme. Four dNTP concentrations $200,100,50$ and $25 \mu \mathrm{M}$ were tested for the above reaction modified by additional integration of 10 pmol FdUTP (Fermentas International Inc.), and a touchdown PCR programme was compared with the above normal one. The touchdown programme consisted of $94^{\circ}$ for 4 min; 20 cycles of $94^{\circ}$ for $30 \mathrm{~s}, 70-60^{\circ}$ or $66-56^{\circ}$ for $30 \mathrm{~s}$ with a decrease of $0.5^{\circ}$ per cycle and $72^{\circ}$ for 1 min; 26 cycles of $94^{\circ}$ for $30 \mathrm{~s}, 60^{\circ}$ or $56^{\circ}$ for $30 \mathrm{~s}$ and $72^{\circ}$ for $1 \mathrm{~min}$; and a final extension at $72^{\circ}$ for $10 \mathrm{~min}$. The PCR products $(5 \mu \mathrm{L})$ were initially checked through agarose gel electrophoresis as mentioned above.

Detection of each SSR was then performed on an ABI 3130xl genetic analyser (Applied Biosystems, Foster City, CA, USA). The PCR products $(1 \mu \mathrm{L})$ were diluted 1:10.5 with loading buffer [9.34 $\mu \mathrm{L}$ deionized formamide and $0.16 \mu \mathrm{L}$ internal standard GeneScan 500LIZ (ABI)] and then denatured at $95^{\circ}$ for 5 min followed by rapid cooling on ice. The detection procedure was followed the standard module using software GeneMapper 4.0 (ABI), and each allele and its fluorescence intensity (units) were verified by visual inspection.

Six SSRs were chosen for subsequent multiplexed detection of PCR products on the basis that their alleles were unlikely to overlap in size with each other. PCR products of two to six SSRs were mixed with certain volumes depending on amplicon concentration and then diluted to $10.5 \mu \mathrm{L}$ with loading buffer $[V \mu \mathrm{L}$ PCR product mixture, 10.25-V $\mu \mathrm{L}$ deionized formamide and $0.25 \mu \mathrm{L}$ GeneScan 500LIZ (ABI)]. SSR genotyping was conducted as described above.

\section{SSR genotyping over the mapping population}

The SSR markers that could be genotyped successfully in above experiments were initially screened against two parents and six sibs of the mapping population, and those resulting in one to four segregating alleles among the sibs were then used for genotyping over the whole population. PCR and post-PCR detection were carried out as optimised above.

\section{Data analysis}

The PCR optimisation experiment was treated as a randomised complete block design, with dNTP concentration, PCR programme and SSR marker as treatments and each allele per marker as replicate. Statistical analyses were conducted using the software SAS/STAT ${ }^{\circledR}$ version 6.0 (SAS Institute Inc., Cary, NC, USA). Proc Univariate was employed to test normality of the allele fluorescence intensity values detected. Proc GLM procedure (method SS1) was performed following the below mixed linear model to estimate the significance of effects of different factors (treatments) and their interactions:

$$
Y_{i j k l}=\mu+D_{i}+P_{j}+S_{k}+D P_{i k}+P S_{j k}+D P S_{i j k}+A_{l}+E_{i j k l}
$$

where $Y_{i j k l}$ is the fluorescence intensity of the kth SSR marker at the lth allele (replicate) under the ith dNTP concentration and the jth PCR programme; $\mu$ is an overall mean; $D_{i}$ is the effect of the ith dNTP concentration; $P_{j}$ is the effect of the jth PCR programme; $S_{k}$ is the effect of the $\mathrm{k} t h$ SSR marker; $D P_{i j}$ is the interaction effect between the ith dNTP concentration and the jth PCR programme; $D S_{i k}$ is the interaction between the $\mathrm{i} t h$ $\mathrm{dNTP}$ concentration and the $\mathrm{k} t h \mathrm{SSR}$ marker; $P S_{j k}$ is the interaction between the jth PCR programme and the $\mathrm{k} t h$ SSR marker; $D P S_{i j k}$ is the interaction among the ith dNTP concentration, the jth PCR programme and the $\mathrm{k} t h$ SSR marker; $A_{l}$ is the fixed effect of the lth allele (replicate) and $E_{i j k l}$ is the residual error. In addition, CORR procedure was used to calculate the correlations between dNTP concentration and allele fluorescent intensity as well as, in post-PCR multiplexed detection, between the uni-plex fluorescence intensity and the mean over a specific multiplexing level.

The segregating SSR markers were tested for Mendelian inheritance using good-of-fit $\chi^{2}$ test $(P<0.05)$ 
and then integrated in linkage analysis with random amplified polymorphic DNA markers (RAPDs) mapped previously (GAN et al., 2003). Significant linkages were determined at a minimal LOD of 3.0 and a maximal recombination fraction $(\theta)$ of 0.35 under the backcross model using the software Mapmaker (LINCOLN et al., 1992). When necessary, the order of RAPD loci was forced to conform to previously published linkage maps of E. urophylla and E. tereticornis (GAN et al., 2003).

\section{Results and Discussion}

\section{PCR optimisation}

Of the 12 SSR markers selected, 11 could be genotyped successfully by F-dUTP labelling method, with the exceptional case in Embra177 that did not show any fluorescent signal under all conditions. The reason for the failure in F-dUTP labelling with Embra177 was unknown and needed to be explored further. Probably, higher F-dUTP dosage will increase its competitive incorporation into PCR products and thus lead to improved fluorescent signal.

PCR programme, dNTP concentration and SSR marker did have significant effects on allele fluorescence intensity $(P<0.001)$, while their interactions were not significant $(P>0.05$; Table 2$)$. The touchdown PCR pro- gramme resulted always in stronger fluorescent signals than the normal one, and dNTP concentration was negatively significantly correlated with fluorescence intensity $(r=-0.37, P<0.001)$. The touchdown PCR programme and low dNTP concentration may help to accelerate the competitive integration of F-dUTP over dTTP into DNA molecules in amplification and thereby improve the fluorescence intensity of amplicons. Thus, the optimal condition for F-dUTP based SSR genotyping could be a combination of $25 \mu \mathrm{M}$ dNTP in PCR reaction and a touchdown amplification programme. Compared with previous reports (Table 3; MAGNUSSON et al., 1996; KLEVYTSKA et al., 2001; NAGARAJU et al., 2002; GILMORE and Peakall, 2003; Williams and Dewoody, 2003; MAcAvoy et al., 2007; WoolBRIGHT et al., 2008; Busch et al., 2009), our protocol can improve significantly the signal intensity and should thus be valuable for effective detection of SSR alleles that may be otherwise biased or missed due to weak or nil fluorescence. Figure 1 shows the comparison between PCR programmes and among dNTP concentrations in allele fluorescence intensity for marker Embra189.

In addition, we tested F-dUTP from Roche Diagnostics GmbH (Mannheim, Germany) under the optimal condition illustrated above, and found that the signal intensity is nearly equivalent to that of Fermentas (data not

Table 2. - Variance analysis of the effects of PCR programme, dNTP concentration, SSR marker and their interactions on allele fluorescence intensity in F-dUTP incorporated PCR optimisation. Asterisks indicate significance at 0.001 level. NS, non-significance at 0.05 level.

\begin{tabular}{lrrrr}
\hline Source & d.f. & Sum of squares & Mean square & \multicolumn{1}{c}{ F value } \\
\hline Replicate or allele & 1 & 114122.2 & 114122.2 & $0.27^{\mathrm{NS}}$ \\
PCR programme $(P)$ & 1 & 5349825.3 & 5349825.3 & $12.51^{\text {*** }}$ \\
dNTP concentration $(D)$ & 3 & 34376751.9 & 11458917.3 & $26.79^{\text {*** }}$ \\
SSR marker $(S)$ & 10 & 125232398.6 & 12523239.9 & $29.27^{* * *}$ \\
$P \times D$ & 3 & 513432.8 & 171144.3 & $0.40^{\mathrm{NS}}$ \\
$P \times S$ & 10 & 2736193.1 & 273619.3 & $0.64^{\mathrm{NS}}$ \\
$D \times S$ & 30 & 17315863.5 & 577195.4 & $1.35^{\mathrm{NS}}$ \\
$P \times D \times S$ & 30 & 6890947.9 & 229698.3 & $0.54^{\mathrm{NS}}$ \\
Error & 71 & 30372567.8 & 427782.6 & \\
\hline
\end{tabular}

Table 3. - Comparison of the protocols used for F-dUTP based SSR genotyping. The normal and touchdown PCR programmes cited may differ from those of this paper in number of cycles as well as temperature and time designated for each step. The maximal multiplex of 2 by Gilmore and PEAKall (2003) is based on 2 types of F-dUTP, each labelled with a specific fluorescent dye. PE, Perkin-Elmer (Foster City, USA). ABI, Applied Biosystems. NS, not specified.

\begin{tabular}{|c|c|c|c|c|c|c|c|}
\hline \multirow[t]{3}{*}{ No. } & \multirow[t]{3}{*}{ F-dUTP supplier } & \multicolumn{3}{|c|}{ PCR reaction } & \multirow{3}{*}{$\begin{array}{c}\text { PCR } \\
\text { programme }\end{array}$} & \multirow{3}{*}{$\begin{array}{l}\text { Maximal } \\
\text { multiplex }\end{array}$} & \multirow[t]{3}{*}{ Reference } \\
\hline & & & {$[\mathrm{dNTP}]$} & & & & \\
\hline & & $(\mu \mathrm{L})$ & $(\mu \mathrm{M})$ & $(\mathrm{pmol})$ & & & \\
\hline 1 & $\mathrm{PE}$ & 50 & 200 & 50 & Normal & 1 & MAGNUSSON et al., 1996 \\
\hline 2 & $\mathrm{ABI}$ & 20 & 200 & 20 & Normal & 1 & KLEVYTSKA et al., 2001 \\
\hline 3 & $\mathrm{PE}$ & 5 & 50 & 10 & Normal & 2 or more & NAGARAJU et al., 2002 \\
\hline 4 & $\mathrm{ABI}$ & 10 & 250 & 24 & Normal & (2) & Gilmore and Peakall, 2003 \\
\hline \multirow[t]{2}{*}{5} & Molecular Probes & 12 & 200 & $1000(\mathrm{R} 110)$ & Normal & 1 & Williams and Dewoody, 2003 \\
\hline & & & & 4000 (TAMRA) & & & \\
\hline 6 & Roche & 25 & 100 & 25 & Touchdown & 1 & MacAvoy et al., 2007 \\
\hline 7 & Roche & 15 & 200 & 10 & Normal & NS & Woolbright et al., 2008 \\
\hline 8 & $\mathrm{ABI}$ & 25 & 200 & $12.5-50$ & Normal & NS & Busch et al., 2009 \\
\hline 9 & Fermentas & 10 & 25 & 10 & Touchdown & 6 & This paper \\
\hline
\end{tabular}


A

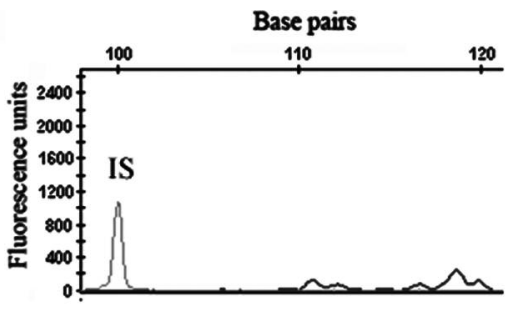

B

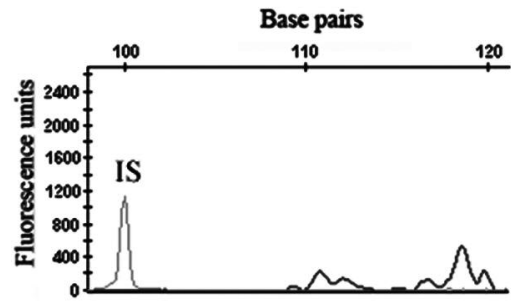

C

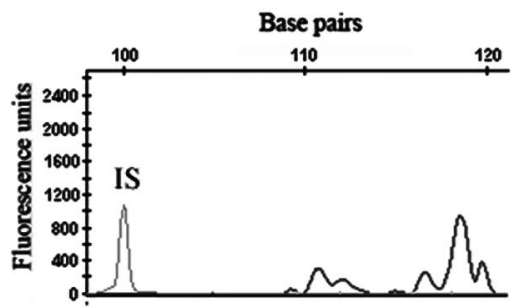

D

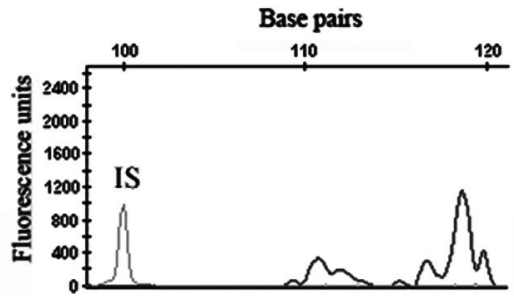

E

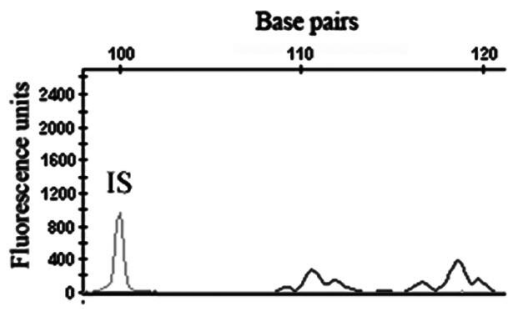

$\mathbf{F}$

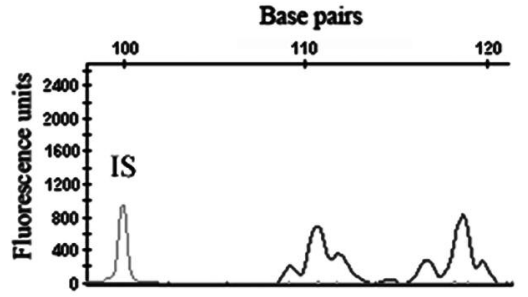

$\mathbf{G}$

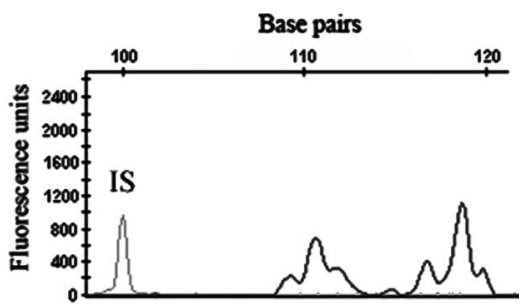

H

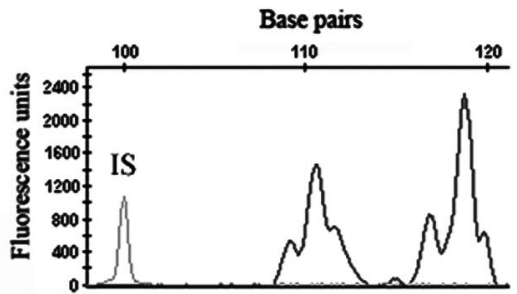

Figure 1. - Effects of dNTP concentration and PCR programme on allele fluorescent intensity of SSR marker Embra189 amplified with $\mathrm{P}_{1}$. The two alleles were $110 \mathrm{bp}$ and $118 \mathrm{bp}$ in size. A-D, normal PCR programme; E-H, touchdown PCR programme; A and E, $200 \mu \mathrm{M}$ dNTP in PCR reaction; B and F, $100 \mu \mathrm{M}$ dNTP; C and G, $50 \mu \mathrm{M}$ dNTP; D and H, $25 \mu \mathrm{M}$ dNTP. IS: internal standard.

shown) though the latter was much cheaper, that is, about US\$ 120 and 350 per $25 \mathrm{nmol}$ of Fermentas and Roche, respectively.

The major advantage of F-dUTP method over primer labelling in automated SSR genotyping is to forego the considerable expense on fluorescent primers for markers that are not yet known to be polymorphic (WiLliams and DEWOODY, 2003), and the method is therefore extremely attractive in screening polymorphic SSRs (KLEVYTSKA et al., 2001; GILMORE and PEAKALl, 2003; Busch et al., 2009). Also, in case that the sample size is not very large, such an advantage holds true even compared with the universal M13 primer labelling, an economical method recognized widely. Taking Fermentas F-dUTP for example, for a given SSR marker, the cost for 100 samples (10 pmol per sample) is only US $\$ 4.8$, which is still slightly less than that of M13 primer method in which the dosage of fluorescent primer (US $\$ 100-130$ per $50 \mathrm{nmol}$ ) costs at least US $\$ 2.0$ and the fusion of M13 primer sequence with one of the original SSR primers does about US $\$ 3.0$.
However, the above advantage will diminish with the increase of sample size, especially when an expensive source of F-dUTP is included, such as ABI (around US $\$ 400$ per $25 \mathrm{nmol}$ ). Further, the F-dUTP method is disadvantageous in that the usually used dye appears blue and loci are indistinguishable on the basis of fluorescence colour when visualized on an automated sequencer (Williams and Dewoody, 2003). This would be unfavourable for post-PCR multiplexed detection, especially when the fluorescent signal is relatively weak following the routine PCR protocols, and thereby compromise its economic strength stated above. These are probably the reasons that some authors used fluorescent primers to investigate a larger size of samples though FdUTP (ABI) was employed in screening marker polymorphisms (KLEVYTSKa et al., 2001; GILMORE and PeaKall, 2003; Busch et al., 2009). Nevertheless, as demonstrated by NAGARAJU et al. (2002) and in this study (see below), the method can be improved for multiplexing if various SSR markers be size-fractionated sufficiently and fluorescence intensity of the alleles be 
strong enough. In addition, utilization of two or more FdUTP types, each labelled with a specific fluorescent colour (maybe more expensive than the blue dye), would do help in this respect (NAGARAJU et al., 2002; BusCH et al., 2009).

\section{Post-PCR multiplexed detection}

Despite that the volume of PCR products applied to multiplexed detection was half $(0.5 \mu \mathrm{L}$; Embra227 and Embra147), equivalent $(1.0 \mu \mathrm{L} ; \quad$ Embra116 and Embra189) or double (2.0 $\mu \mathrm{L}$; Embra203 and Embra29) of that of the uni-plex set, all the alleles decreased dramatically in fluorescence intensity with increased multiplexing level (Table 4), though there were some fluctuations with marker combination. Moreover, the mean allele fluorescent intensity over a multiplexing level was significantly correlated with the uni-plex performance, with $r=0.71-0.98(P<0.02)$ except for 4 -plexed case with $r=0.64(P=0.08)$.

As signals with less than 100 fluorescence units were usually ambiguous in sequencer-based SSR scoring, a multiplexing level could be acceptable only if all of the alleles involved, besides sufficient fractioning of their size, would retain the minimal fluorescence intensity as required. Based upon the multiplexing results (Table 4), the uni-plex fluorescence, especially that of the weaker allele of a marker when applicable, should be a critical factor allowing the maximal multiplexing level, and a principle guideline would be of hexa- (or higher), penta-, tetra-, tri-, di- and uni-plexing for markers with $>2000$, 1500-2000, 1000-1500, 500-1000, 200-500 and < 200 fluorescence units, respectively. Therefore, it was recommended for the 11 SSR markers detectable in this study to be uni- or multi-plexed into five panels, including Panel I (uni-plexed) for Embra173, Panel II (uni-plexed) for Embra203, Panel III (di-plexed) for Embra29 and Embra139, Panel IV (tri-plexed) for Embra147, Embra116 and Embra333 and Panel V (hexa-plexed) for Embra186, Embra189, Embra219 and Embra227. Nevertheless, Embra189 and Embra147 could be tetraplexed if appropriate markers were adequately included.

The maximal multiplexing level reported here is higher than those described previously for F-dUTP based SSR genotyping (Table 3; MAGNUSSON et al., 1996;
KLEVYTSKA et al., 2001; NAGARAJU et al., 2002; GilmoRE and Peakall, 2003; Williams and Dewoody, 2003; MACAvoy et al., 2007; WoOLBRIGHT et al., 2008; BusCH et al., 2009). This would thus contribute greatly to increase the throughput of genotyping and decrease the expense on sequencer-related reagents and consumables, including internal standard, gel and capillary array. For instance, a mean of tri-plex will save up to US $\$ 0.67$ per reaction (one sample $x$ one marker) as compared with the commonly used uni-plex detection (about US \$1.0) on $3130 x \mathrm{x}$ (ABI).

The multiplexing level is also comparable to the fluorescent primer based assay, e.g. hexa-plexing in a bacterium Yersinia pestis (KLEVYTSKA et al., 2001) as well as tri- to tetra-plexing in pinyon jay (Gymnorhinus cyanocephalus; Busch et al., 2009), and post-PCR multiplexed detection is thereafter not a disadvantage even with a single type of F-dUTP. In other words, the economic advantage of the F-dUTP method mentioned earlier could be guaranteed, especially for a cheaper source of F-dUTP and not very large sample size. For instance, the cost of Fermentas F-dUTP for 2000 samples for a certain marker (10 pmol per sample or reaction) would be US $\$ 96$, which is still less than that of labelling a fluorescent primer, albeit in rare cases do samples reach so large a number of 2000 .

\section{Genetic mapping}

Of the 11 SSR markers genotyped, nine and one presented allelic segregation for both parents and for only the paternal $E$. tereticornis parent, respectively, while one (Embra333) showed a monomorphic allele over the mapping population (Table 1). The $\chi^{2}$ test indicated that three SSRs distorted significantly from expected Mendelian segregation ratios $(P<0.05$; Table 1$)$, including Embra139 that was also observed to segregate aberrantly in a mapping population of $E$. urophylla $\mathrm{x}$ E. grandis (BRONDANI et al., 2006).

Totally six markers were mapped to four linkage groups (Figure 2). Three markers Embra189, Embra173 and Embra186 were assigned to separate linkage groups for both parental species while three other SSRs (Embra 116, Embra203 and Embra139) were mapped onto a single linkage group (Et-LG12) of paternal E. tereticornis.

Table 4. - Mean allele fluorescence intensity (units) in post-PCR multiplexed detection of two to six SSR markers. NA, not available due to absence at a specific multiplexed level.

\begin{tabular}{lccccccc}
\hline Marker & Allele & Uni-plex & 2-plexed & 3-plexed & 4-plexed & 5-plexed & 6-plexed \\
\hline Embra227 & $300 \mathrm{bp}$ & 1517 & 891 & 426 & 157 & 42 & 57 \\
& $304 \mathrm{bp}$ & 1884 & 1329 & 643 & 223 & 56 & 107 \\
Embra147 & $171 \mathrm{bp}$ & 894 & 410 & 158 & 182 & 93 & 104 \\
& $183 \mathrm{bp}$ & 2179 & 1353 & 701 & 273 & 175 & 154 \\
Embra116 & $122 \mathrm{bp}$ & 1575 & 856 & 436 & 98 & 58 & 95 \\
Embra189 & $110 \mathrm{bp}$ & 1468 & $\mathrm{NA}$ & $\mathrm{NA}$ & 316 & 109 & 131 \\
& $118 \mathrm{bp}$ & 2323 & $\mathrm{NA}$ & $\mathrm{NA}$ & 671 & 453 & 433 \\
Embra203 & $336 \mathrm{bp}$ & 166 & 94 & 55 & 35 & $\mathrm{NA}$ & 17 \\
& $340 \mathrm{bp}$ & 478 & 260 & 146 & 73 & $\mathrm{NA}$ & 50 \\
Embra29 & $260 \mathrm{bp}$ & 436 & 237 & 39 & 26 & 23 & 32 \\
\hline Overall mean & & 1292 & 619 & 344 & 205 & 126 & 118 \\
\hline
\end{tabular}



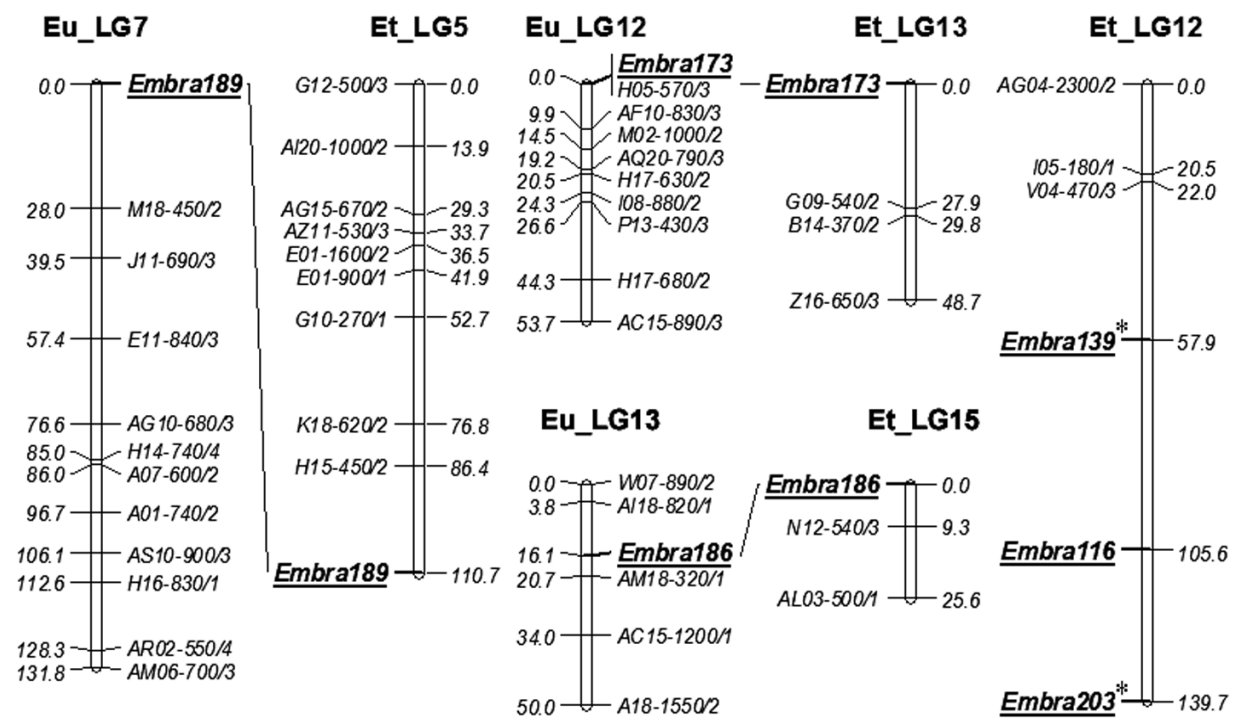

Figure 2. - Position of the SSRs assigned to E. urophylla and E. tereticornis RAPD linkage maps constructed previously (GAN et al., 2003). SSR markers are shown in underlined bold. The cumulative distances in centiMorgans (Kosambi) are given at the left of the bar for $E$. urophylla $(\mathrm{Eu})$ and the right for E. tereticornis (Et) linkage groups. Asterisks indicate markers with segregation distortion $(P<0.05)$.

The four linkage groups corresponded to separate counterparts of BRONDANI et al. (2006), indicating the potential of such consensus SSRs for comparative mapping and comprehensive map construction in the genus Eucalyptus. However, the order of and the distances between the three SSRs mapped to Et_LG12 were different from the linkage group 8 of BRONDANI et al. (2006). Such a difference could be due to either sex or species effect or sampling error (GION et al., 2000).

\section{Conclusions}

The protocol optimised here has the advantages in significantly increased fluorescence intensity and relatively low F-dUTP cost for sequencer-based SSR genotyping. It is compatible with established systems for automated high-throughput DNA fragment analysis, and has been applied effectively to genetic mapping of SSR loci in Eucalyptus. The increase in allele fluorescence intensity will improve the reliability in scoring markers and allow a higher level of multiplexing in post-PCR detection. The protocol provides an economical and reliable highthroughput alternative for SSR genotyping and will have broad applications as the number of available SSR markers is increasing and their utility continues to expand for multiple species.

\section{Acknowledgements}

This work was supported by the National Natural Science Foundation of China (No. 31070592), Guangdong Natural Science Foundation (No. 10151052001000000), and the Ministry of Finance of China through a specific programme for national non-profit scientific institutions (Nos. RITFKYYW2008-4 and 2010-04). We thank Dr. XINYe ZhANG (University of Tennessee, USA) for encouraging discussion and an anonymous reviewer for valuable comments.

\section{References}

Agrama, H. A., T. L. George and A. F. Salah (2002): Construction of genome map for Eucalyptus camaldulensis Dehn. Silvae Genet. 51: 201-206.

Brondani, R. P. V., C. Brondani, R. TARChini and D. GratTAPAGLIA (1998): Development, characterization and mapping of microsatellite markers in Eucalyptus grandis and E. urophylla. Theor. Appl. Genet. 97: 816-827.

Brondani, R. P. V., E. R. Williams, C. Brondani and D. Grattapaglia (2006): A microsatellite-based consensus linkage map for species of Eucalyptus and a novel set of 230 microsatellite markers for the genus. BMC Plant Biol. 6: 20.

Busch, J. D., R. Benford, T. Pearson, E. Palmer, R. P. BALDA and P. KEIM (2009): Development of polymorphic tetranucleotide microsatellites for pinyon jays (Gymnorhinus yanocephalus). Conserv. Genet. 10: 689-691.

Doyle, J. J. and D. J. Doyle (1990): Isolation of plant DNA from fresh tissue. Focus 12: 13-15.

FAO (2000): Global forest resources assessment 2000 main report. FAO, Rome.

GAN, S., J. SHI, M. LI, K. WU, J. WU and J. BAI (2003): Moderate-density molecular maps of Eucalyptus urophylla S. T. Blake and E. tereticornis Smith genomes based on RAPD markers. Genetica 118: 59-67.

Gilmore, S. and R. PEAKAll (2003): Isolation of microsatellite markers in Cannnabis sativa L. (marijuana). Mol. Ecol. Notes 3: 105-107.

Gion, J.-M., P. RECH, J. Grima-Pettenati, J. Verhaegen and C. Plomion (2000): Mapping candidate genes in Eucalyptus with emphasis on lignification genes. Mol. Breed. 6: 441-449.

GRATTAPAGLIA, D. and M. Kirst (2008): Eucalyptus applied genomics: from gene sequences to breeding tools. New Phytol. 179: 911-929.

Jones, R. C., D. A. Steane, B. M. Potts and R. E. VailLANCOURT (2002): Microsatellite and morphological analysis of Eucalyptus globulus populations. Can. J. For. Res. 32: 59-66. 
Klevytska, A. M., L. B. Price, J. M. Schupp, P. L. WorSHAM, J. WoNG and P. KeIM (2001): Identification and characterization of variable-number tandem repeats in the Yersinia pestis genome. J. Clin. Microbiol. 39: 3179-3185.

LINCOLN, S., M. DALY and E. LANDER (1992): Constructing genetic maps with MAPMAKER/EXP 3.0. Whitehead Institute technical report, $3^{\text {rd }}$ edition. Whitehead Institute, Cambridge, MA.

MacAvoy, E. S., L. M. McGibbon, J. P. Sainsbury, H. Lawrence, C. A. Wilson, C. H. Daugherty and G. K. ChAmBers (2007): Genetic variation in island populations of tuatara (Sphenodon spp) inferred from microsatellite markers. Conserv. Genet. 8: 305-318.

Magnusson, P. K. E., E. Wilander and U. Gyllensten (1996): Analysis of loss of heterozygosity in microdissected tumor cells from cervical carcinoma using fluorescent dUTP labeling of PCR products. BioTechniques 21: 844-847.

Nagaraju, J., M. Kathirvel, R. R. Kumar, E. A. SiddiQ and S. E. HASNAIN (2002): Genetic analysis of traditional and evolved Basmati and non-Basmati rice varieties by using fluorescence-based ISSR-PCR and SSR markers. Proc. Natl. Acad. Sci. USA 99: 5836-5841.

NGuYen, H. T. and X. Wu (2005): Molecular marker systems for genetic mapping. In: The handbook of plant genome mapping: genetic and physical mapping, eds. K. MeKsem and G. KAHL. WILEY-VCH Verlag GmbH \& Co. KgaA, Weinheim, Germany. 23-52.

Ottewell, K. M., S. C. Donnellan, G. F. Moran and D. C. PAton (2005): Multiplexed microsatellite markers for the genetic analysis of Eucalyptus leucoxylon (Myrtaceae) and their utility for ecological and breeding studies in other Eucalyptus species. J. Hered. 96: 445-451.
Pashley, C. H., J. R. Ellis, D. E. McCauley and J. M. BURKE (2006): EST databases as a source for molecular markers: lessons from Helianthus. J. Hered. 97: 381-388.

Powell, W., G. C. Machray and J. Provan (1996): Polymorphisms revealed by simple sequence repeats. Trend. Plant Sci. 1: 215-222.

SCHLÖTTERER, C. (2004): The evolution of molecular markers-just a matter of fashion? Nat. Rev. Genet. 5: 63-69.

SCHUELKE, M. (2000): An economic method for the fluorescent labeling of PCR fragments. Nat. Biotech. 18: 233-234.

TAUZ, D. (1989): Hypervariability of simple sequences as a general source for polymorphic DNA markers. Nucleic Acids Res. 16: 6463-6471.

Thamarus, K., K. Groom, J. Murrell, M. Byrne and G. F. MoraN (2002): A genetic linkage map for Eucalyptus globulus with candidate loci for wood, fibre and floral traits. Theor. Appl. Genet. 104: 379-387.

Williams, R. D. and J. A. Dewoody (2003): Fluorescent dUTP helps characterize 10 novel tetranucleotide microsatellites from an enriched salamander (Ambystoma texanum) genomic library. Mol. Ecol. Notes 4: $17-19$.

Woolbright, S. A., S. P. DiFazio, T. Yin, G. D. Martinsen, X. Zhang, G. J. Allan, T. G. Whitham and P. Keim (2008): A dense linkage map of hybrid cottonwood (Populus fremontii $\times P$. angustifolia) contributes to longterm ecological research and comparison mapping in a model forest tree. Heredity 100: 59-70.

Yasodha, R., R. Sumathi, P. Chezhian, S. Kavitha and M. GHosh (2008): Eucalyptus microsatellites mined in silico: survey and evaluation. J. Genet. 87: 21-25.

\title{
Two-dimensional penalized splines via Gibbs sampling to account for spatial variability in forest genetic trials with small amount of information available
}

\author{
By E. P. CAPPA ${ }^{1), *}$, M. LstibUReK ${ }^{2)}$, A. D. YANCHUK ${ }^{3), 4)}$ and Y. A. El-KassabY ${ }^{4)}$
}

(Received $14^{\text {th }}$ January 2010)

\footnotetext{
1) Instituto Nacional de Tecnología Agropecuaria (INTA), Instituto de Recursos Biológicos, De Los Reseros y Dr. Nicolás Repetto $\mathrm{s} / \mathrm{n}, 1686$, Hurlingham, Buenos Aires, Argentina.

2) Department of Dendrology and Forest Tree Breeding, Faculty of Forestry and Wood Sciences, Czech University of Life Sciences Prague, Kamycka 129, 16521 Praha 6, Czech Republic.

$\left.{ }^{3}\right)$ British Columbia Forest Service, Tree Improvement Branch, Victoria, British Columbia, V8W 9C2 Canada.

4) Department of Forest Sciences, Faculty of Forestry, University of British Columbia, 2424 Main Mall, Vancouver, British Columbia, V6T 1 Z4 Canada.

*) Corresponding author: Eduardo Pablo Cappa. Bosques Cultivados Instituto de Recursos Biológicos, Centro de Investigación en Recursos Naturales, Instituto Nacional de Tecnología Agropecuaria, De Los Reseros y Dr. Nicolás Repetto s/n, 1686 Hurlingham, Buenos Aires, Argentina. Phone: +54 114621 0433, Fax: +54 114621 0433. E-mail: ecappa@cnia.inta.gov.ar
}

\begin{abstract}
Spatial environmental heterogeneity are well known characteristics of field forest genetic trials, even in small experiments ( $<1 \mathrm{ha})$ established under seemingly uniform conditions and intensive site management. In such trials, it is commonly assumed that any simple type of experimental field design based on randomization theory, as a completely randomized design (CRD), should account for any of the minor site variability. However, most published results indicate that in these types of trials harbor a large component of the spatial variation which commonly resides in the error term. Here we applied a two-dimensional smoothed surface in an individual-tree mixed model, using tensor product of linear, quadratic and cubic B-spline bases with different and equal number of knots for rows and columns, to account
\end{abstract}

